\title{
Sexual Desire and Fantasies in the LGBT+ Community: Focus on Lesbian Women and Gay Men
}

\author{
Filippo Maria Nimbi ${ }^{1}$ (D) Giacomo Ciocca ${ }^{1}$ Erika Limoncin ${ }^{2} \cdot$ Lilybeth Fontanesi $^{3}$ - Ünal Batuhan Uysal ${ }^{4}$. \\ Matthew Flinchum ${ }^{5} \cdot$ Renata Tambelli $^{1} \cdot$ Emmanuele Angelo Jannini $^{2} \cdot$ Chiara Simonelli $^{1}$
}

Published online: 28 July 2020

(C) The Author(s) 2020

\begin{abstract}
Purpose of Review The purpose of this review is to summarize the current knowledge around sexual desire, fantasies, and related biopsychosocial factors that may facilitate or obstruct sexual expressions in lesbian women and gay men.

Recent Findings Sexual desire levels and related problems do not seem significantly different in people who identify as gay or lesbian compared to their heterosexual counterparts. Evidence has shown lesbian women and gay men may have specific desire expressions and biopsychosocial factors influencing their sexual health. This may suggest the importance of deepening the understanding of the unique factors of LGBT+ sexuality and relationships while paying attention to the sociocultural background in which lesbian and gay people grow and develop their identities.

Summary A lack of specific and unbiased literature on sexual desire and fantasies in gay and lesbian people is reported. Available evidence is controversial and often biased. LG people showed a variety of sexual expressions that are hard to categorize referring to the heteronormative sexual standards that permeate literature and clinical practice. Implications for future research and clinical practice are discussed.
\end{abstract}

Keywords Lesbian $\cdot$ Gay $\cdot$ Sexual desire $\cdot$ Sexual fantasy $\cdot$ Sexual orientation $\cdot$ Sex positive

\section{Introduction}

Defining sexual desire is more challenging than any other sexual response phase. It is typically defined as the subjective

This article is part of the Topical Collection on Urology, Gynecology, and Endocrinology

Filippo Maria Nimbi

Filippo.nimbi@uniroma1.it

1 Department of Dynamic and Clinical Psychology, Sapienza University of Rome, Via degli Apuli 1, 00185 Rome, Italy

2 Department of Systems Medicine, University Tor Vergata, Rome, Italy

3 Department of Psychological, Health and Territorial Sciences, University G. D'Annunzio of Chieti-Pescara, Chieti, Italy

4 Department of General Psychology, University of Padua, Padua, Italy

5 Texas A\&M University Central Texas, 1001 Leadership Place, Killeen, TX 76549, USA psychological status to initiate and maintain human sexual behavior which can be triggered by external (a person, pornography) and internal stimuli (sexual fantasies) $[1,2 \bullet \bullet]$. It was first conceptualized by Kaplan [3, 4] as the appetitive phase preceding arousal, orgasm, and resolution. More recently, some authors $[5,6]$ placed desire and arousal in close connection, describing sexual drive as a predisposition to subjectively respond to sexual stimuli with feelings of sexual excitement. However, our current knowledge is far from adequate to describe sexual desire [2••]. Expressions of desire are different among individuals and within the same person, ranging from momentary fluctuations during the day to broad changes over life [7]. Thus, it represents the most difficult area to deal with in research and sexual therapy in the authors' perspective.

Researchers have tried to highlight gender differences starting from the evidence that men show higher sexual desire than women. The nature/nurture debate on this topic is still ongoing without resolution [8, 9]. However, researchers are moving towards a more holistic understanding of sexual functioning, recognizing the importance of similarities between genders and contemplating an in-depth analysis of 
interindividual variance within genders and inside the couple $[2 \bullet \bullet]$. Research on desire in sexual orientations has followed the debate-line of gender differences: early studies have tried to find scientific evidences to state that lesbian women and gay men were different and more pathological than were heterosexual people in their sexual behavior $[10,11]$.

The aim of the present review was to discuss the current knowledge about sexual desire and its manifestations focusing on lesbian women and gay men with attention to directions for future research and clinical practice.

\section{Methods}

The manuscripts used for this review were collected based on the results of a bibliographic research of relevant articles in Cochrane Library, Google Scholar, Web of Science, Scopus, and EBSCO. The search terms used, including asterisks, were "sexual desire," "LGBT," "Lesbian," "Gay," "Women who have Sex with Women (WSW)," "Men who have Sex with Men (MSM)," and related terms. Additional terms included "sex* drive," "sex* fantasies," "sex* motivation," "sex* arousal," and "sex* interest". The results were reviewed following the aims of the current work. Experimental studies focusing on different expressions of sexual desire and biopsychosocial factors associated were selected. Books, systematic reviews, and meta-analyses describing models, guidelines, gold standards, treatment algorithms, and critical issues were also considered for a better characterization of the topic. Excluded studies were unrelated to the scope of this review (e.g., focusing only on heterosexual desire). Article references were reviewed to find additional papers. All papers selected were published in English and full texts were accessible. When articles were not directly available, authors were solicited by e-mail.

\section{Results}

A total of 100 papers and other sources were included in the present review, indicating growth in the body of research regarding LGBT+ sexual desire over the last several years. In the early 1980s, many sexual researchers and clinicians started to focus on same-sex sexual and romantic relationships. In addition to the need of addressing the peculiar needs of homosexual people in therapy, many sexologists were also motivated by the possibility of finding new clues on the long-standing gender debate. Many believed that comparing lesbian, gay, and heterosexual people could increase the knowledge of sexual and gender identity [12].

\section{Lesbian Women}

Cultural background has strongly influenced the western understanding of lesbian sexuality. Stereotypes about lesbians usually portray them as extremely masculine or feminine (mirroring heterosexual gender roles) and tend to oversimplify their sexual experience. Heteronormativity assumes that lesbians cannot achieve real sexual satisfaction without the presence of men. Pornography usually portrays it featuring sex between femme lesbian women as an erotic preliminary game, until a man joins the scene bringing desire, pleasure, and satisfaction. Female sexual desire is performed for the benefit of men, and the sexual gratification is usually not contemplated in the absence of men [13]. Thus, same-sex desire tends to be invisible and silenced [14]. Similarly, stereotypic expectations about relationships assume that lesbians are likely to imitate heteronormative gender roles in monogamous, married, fused, and motherhood-oriented couples [13].

\section{Levels of Sexual Desire}

Following these premises, the stereotypic expectation on lesbian sexuality could be defined as having less sexual frequency and desire because the "drive-bringer" male figure is missing, whereas more importance is given to relationship and intimacy. Early studies on sexual frequency reported a lower rate of sexual activity in lesbian compared to heterosexual women [15]. The term "lesbian bed death (LBD)" was coined to indicate a decrease of sexual frequency and desire in lesbian couples after 1-2 years in long-term relationships [16]. This unfriendly term suggested that LBD is a lesbian-specific phenomenon referred to the quantity of sexual activity, devaluing the importance of quality in sexual experience [17••]. LBD is based on the idea of the existence of a standard frequency of sexual activity in couples [18], and sexual distress is not contemplated in most of these studies.

Multiple theories have tried to explain LBD and its peculiarities [12, 19-23]. These theories have focused mainly on sociocultural and relationship factors, such as being less sexually assertive, experiencing more guilt and conflicts in sexuality, having the tendency to become over-fused and merged in relationships, and reporting high rates of sexual trauma and internalized homophobia. Despite some early evidence, recent literature $[24,25]$ has highlighted that LBD lacks definitional clarity and empirical validity, and it expresses a stereotypical understanding of lesbian sexuality where personal distress is neglected. Moreover, prolonging the LBD discussion may exacerbate the importance of quantity over quality in sexuality, fostering a performance-based view of sexual experience $[2 \bullet \bullet]$. Today, clinicians should work on sexual satisfaction, tailoring treatment to patients' aims rather than on sexual standards. 
Other, more numerous studies [12, 22-33] have reported no difference in sexual frequency for sexual orientation in women. When differences were found, higher rates of sexual activity and desire were reported by lesbian rather than heterosexual women. Cohen and Byers [25] demonstrated that most WSW in long-term same-sex relationships engaged once a day or more in non-genital sexual activities (e.g., cuddling, kissing) and once a week or more in genital sex (e.g. touching breasts/genitals, oral sex, masturbation) during the previous month. These factors were related to more positive sexual esteem, minimal anxiety, and less negative automatic thoughts during sexual activity. In this study, both genital sexual frequency and sexual desire were significant predictors of sexual satisfaction, suggesting them as important components for same-sex relationship and well-being in WSW [34].

Furthermore, lesbian and bisexual women reported lower rates of hypoactive sexual desire disorder (HSDD) compared to heterosexual women [31,33]. Lesbian women seem more likely to have had more sexual partners, to consider sex as an important aspect of their lives, to reach orgasm more often, and to be more satisfied by the frequency of sexual activity than heterosexual women [27]. Moreover, lesbian couples reported significantly longer sexual encounters than gay men and heterosexual men and women [35].

Another important belief regarding lesbian women is represented by the exaltation of emotions and monogamy in their relationships. This idea may have contributed to diffusion and maintenance of the LBD myth. In their romantic relationships, some lesbian couples showed a lack of emotional and intimate boundaries between partners [36], and, similar to women in heterosexual relationships, women in same-sex couples seem to place a great emphasis on emotional intimacy for positive sexual experiences [37, 38]. Umberson et al. [39] provided evidence that lesbian partners emphasized the importance of sexual interactions in their relationship. Sexuality represents a tool to achieve emotional intimacy, and lesbians devote large amounts of time and effort to keep sexuality present and satisfying in their long-term relationships. Overall, same-sex partners showed to be more concordant in their levels of sexual desire and views of intimacy, relationship, and sexual activity than their heterosexual counterparts [38].

\section{Factors Influencing Lesbian Sexual Desire}

The literature has highlighted a similar constellation of factors influencing sexual desire for both heterosexual and lesbian women such as depressive symptoms, relationship satisfaction, sexual functioning, and social support [31]. However, some studies highlighted unique sociocultural factors that may influence lesbian sexual desire [17••]. For example, lesbian women reported diminished sexual desire related to sexual discrimination, minority stress, internalized homophobia, religious perceptions of sexuality as a taboo, sociocultural pressures to conform to heteronormativity, and stronger gender roles expectations [17••, 31]. Sexual cognitions such as "age-related beliefs," "sexual desire as a sin," "conservative attitudes," and "affection primacy" were frequently reported in lesbian women with sexual desire problems [33, 40]. Additionally, Paine et al. [41•] suggested that sexual activity and desire may diminish due to health, aging, and family events in both lesbian and heterosexual women. In lesbian women, these authors additionally emphasized the negative role of weight gain, caregiving for adult parents, and dealing with menopause together with their partner [41•]. However, lesbian women also described an increase in sexual drive as a result of experiencing cultural openness towards sexual diversity, having access to safer and more visible spaces, and having partners that challenged heteronormative and stereotypic gender expectations $[17 \cdot \bullet]$.

\section{Sexual Fantasies}

While fantasies of having a same-sex sexual encounter are quite common in the heterosexual population [42, 43], studies on the sexual fantasies of lesbian women, and WSW more generally, are extremely lacking. One study by Robinson and Parks [44] did not find significant differences between the erotic fantasies of heterosexual and WSW. Most of the fantasies they observed seemed related to sexual relations, non-standard locations (e.g., public settings), and power or dominance contents. Women involved in same-sex relationships seem to be more likely to express the full spectrum of sexual fantasies than other women. Fantasies of WSW seem to more often combine romantic and erotic elements compared to heterosexual women. Many lesbians reported enjoying pornography and sex toys, and they emphasized the importance of discussing their sexual fantasies with their partners $[23,26]$. Data on erotic narratives highlighted that lesbian women seem to focus more on context, on breaking stereotypes and gender roles, than other women $[45,46]$. A more recent Italian study [47 •] found lesbian women reported higher rates of transgressive sexual fantasies (e.g., dirty talk, role play) and lower rates of emotional-romantic ones (e.g., romantic scenes; cuddling) than heterosexual women. However, Bivona et al. [48] reported the presence of rape fantasies such as "being forced to have sex by a woman", "being forced to do oral sex to a woman", and "being raped by a woman" in both lesbian and heterosexual women.

\section{Gay Men}

Early studies found many individuals perceived gay men as mentally ill or sexually perverted $[49,50]$, emphasizing variations in personality and behavior such as anxiety, depression, and addiction [51]. Indeed, ideas such as most gay men engage in a high rate of sexual activity, are involved in risky 
sexual behaviors, have high number of sexual partners, and are not interested in long-term relationships are still common among scientists and clinicians. These beliefs may reflect a historical period in which homosexuality was considered a mental illness [10,11]. Moreover, a large volume of studies on HIV/AIDS have focused on gay men and MSM, indelibly associating these populations with risky sexual behaviors and fostered stigma. Some of the studies discussed in the following paragraphs rely on this background, in which general assumptions regarding gay men are made based on clinical subgroups (such as HIV-positive gay men) or settings (such as gay people recruited in clinics for sexually transmitted infections-STIs). Readers should consider these biases and refrain from drawing general assumptions about gay sexualities.

\section{Level of Sexual Desire}

Regarding levels of sexual desire, studies on the subject draw disparate conclusions. Lippa [52] and Welling [53] reported that MSM had lower level of sexual desire compared to heterosexual men; conversely, Holmberg and Blair [30] showed that gay men scored moderately higher than heterosexual men and women on different expressions of desire (solitary, inside the couple and for an attractive person). In a recent Portuguese study [54], gay men reported higher solitary (masturbation) and attractive person-related sexual desire compared to heterosexual men. The two groups did not differ on partnerrelated sexual desire within the couple. In this case, the partner-related sexual desire was the main predictor for sexual satisfaction, whereas solitary and attractive person-related sexual desire negatively predicted satisfaction.

Inside the 2010 EMIS survey, almost 13,000 UK MSM described what constitute the best sexual life for them [55]. Most of men reported a desire for sex within committed relationships, followed by the need of emotionally and intimately connected sexual experiences. Many MSM expressed a desire for variety and a high frequency of sexual activities in their lives, and some men reported gaining the most sexual and emotional satisfaction out of casual sex contexts (e.g., hookup, one-night stand) [56]. Other gay men reported a high desire for adventurous and exploratory sexual experience, free from social, psychological, and physical harm [55]. Interestingly, older men were less likely to idealize relationships or emotional connections than younger ones. Moreover, older men were more likely to ask for the sexual practices they wanted [55], as a result of a greater experience and consciousness about their own sexual desire and pleasure.

Many studies focused on the presence of higher "pathological" sexual drive in gay men, considering it as either addiction, compulsion, or hypersexuality. Perera et al. [57] reported a high potential rate of sexual addiction in MSM attending STI clinics, highlighting the importance to deliver psychosexual assessment and support in these contexts. Interestingly,
Weinstein et al. [58] showed no significant difference in the rates of sexual compulsivity between gay and heterosexual men, while lesbian women showed higher rates of sexual compulsivity than heterosexual women. Pachankis et al. [59] showed that proximal minority stressors and emotion dysregulation predicted sexual compulsivity, both directly (e.g., peer rejection) and indirectly (e.g., increasing internalized homonegativity), through anxiety and depression. These results may suggest that some MSM-specific (e.g., minority stress, social pressure) and general (e.g., affective dysregulation) factors represent clinical targets to improve MSM sexual health. Acknowledging how stereotypes may influence sexual behavior may also help to better understand sexual compulsion among gay men [60].

Beyond stereotypes, one of the reasons why sexual compulsion was associated with homosexuality is that hypersexual men generally reported non-exclusively heterosexual fantasies and behaviors [61], but an epidemiological study confirming that MSM are at higher risk for sexual addiction than other men is still lacking. In any case, in the opinions of the authors, prevention programs addressing this important topic which follows a sex-positive approach, free of stigma related to high frequency of sexual activity, could be very beneficial for MSM. Regardless of sexual orientation, problematic sexuality is associated with sexual distress, lack of personal control over sexuality, negative impact on quality of life, and moralistic attitudes towards sexuality rather than with high levels of sexual desire and activity [62]. If one associates high level of sexual desire and frequency of sexual activity with a problem, they might fail to recognize sexual diversity.

Interestingly, another body of work has highlighted HSDD as the most frequent sexual dysfunction among gay men together with anodyspareunia [63]. Studies suggested HSDD prevalence rates between 8.3 and $57 \%$ in gay men [64-68]. Using the dual control model of the sexual response [69], in which sexual excitation and inhibition regulate the expression of desire and arousal, Kowalczyk et al. [70] showed that MSM and heterosexual men reported similar propensities for sexual excitation and inhibition due to the risks of failure in sexual performance. However, MSM were more inhibited to the threat of negative sexual response consequences and complained more often of diminished levels of sexual desire compared to other men.

Overall, same-sex partners have shown to be more concordant in their views of intimacy and levels of sexual desire than opposite sex partners [39]. Men in same-sex couples seem to be more likely to agree on having sexual relationships outside the committed relationship (consensual non-monogamous relationships or open couples). This choice does not seem to impact the well-being of the relationship as the partners are able to separate sexuality from emotional intimacy [71]. Gay couples often establish rules to prevent possible emotional bonds with sexual partners outside the relationship [38]. These agreements 
do not seem to influence the emotional work devoted to maintaining intimacy in their long-term relationship [39]. In some cases, the ability to share their sexual repertoire with other people (e.g., threesome, group sex) may improve the sexual intimacy of the couple. However, this benefit depends on how the couple implements said rules, communicate about their feelings, and maintain their boundaries [72•].

That said, generalizing gay relationship with open, nonmonogamous couples is reductive. Many men opt for meaningful and satisfying monogamous long-term relationships based on fidelity, trust, and security. Yet, the non-monogamy stereotype of gay relationships persists, and the desire for monogamy is described as old-fashioned, utopist, or insecure. Such arguments fail to consider the importance for some men to adhere to social norms and cultural values (e.g., family, religion) and the pluralism of emotional investment and forms of subjectivity that monogamy as a cultural ideal may engender [73]. Research on gay relationships and sexual desire indicates that men may find different strategies and compromises to deal with sexual diversity, intimacy, and fidelity [74]. Clinicians should be aware that men could experience tension balancing their desires for stable and secure relationships with sexual opportunities available in the gay community and be mindful of their own prejudices and beliefs [75].

\section{Factors Influencing Gay Sexual Desire}

Although gay and heterosexual men might be more similar than they are different in their experience of sexual drive [30], factors such as negative stereotypes and stigmatization may impact how gay men express and interpret their desire [76, 77]. Bancroft et al. [78] addressed the role of mood in a group of gay men: when facing depressive status, $16 \%$ of men typically experienced increased sexual interest, while $47 \%$ reported a decrease; when experiencing anxiety, 24\% reported an increased sexual drive, whereas $39 \%$ reported a decrease.

Hiding homosexual fantasies and desire is strongly associated with a perceived negative social climate regarding samesex sexual behavior and may be functional for some men in dangerous contexts, such as some Arabic countries [79]. However, it is usually related to worse sexual satisfaction [20]. Coming out and self-disclosure should be better investigated in relation to their possible effects on sexual desire, both at individual and couple level. Creating sexual values inside romantic relationships predicted higher sexual satisfaction and dyadic sexual desire [80].

The HIV pandemic needs a special discourse when it comes to MSM sexual health. Among male sexual minority adolescents and adults, psychosocial concerns, stigma, and perceived vulnerability to HIV are widely common [81]. Even if the HIV-care has incredibly advanced, the "HIV shadow" still has a pervasive influence on gay men sexuality. MSM frequently report more distractive thoughts related to fear of STIs compared to heterosexual men [82]. In a group of Belgian HIV-positive MSM, $15 \%$ of men reported HSDD [83] and factors associated to lower desire were higher frequency of masturbation and having less sexual partners over time. Conversely, some men may cope with a new diagnosis of HIV infection increasing their sexual activity and desire $[78,84]$. This relates to coping strategies to manage high anxiety and depression rates and defense mechanisms such as denial. This reaction to trauma is often associated with higher risk-taking such as substance consumption, unprotected sex, and therapy drop-out. Older age, being single, and less satisfied with general health and sexual desire were factors associated with sexual withdrawal in HIV gay men [85]. It should be noted that prevalence of sexual inactivity has sensibly declined since the diffusion of modern antiretroviral therapy, suggesting a normalization process in HIV-positive men's sexual lives. Nevertheless, HIV fear and stigma may still play an important role in explaining higher rates of sexual desire problems among gay men [63] and should be investigated during sexual health assessments. These results may also suggest the need to deepen the relationship between sexual desire, sexual activity, and reactions to HIV infection in order to improve care.

Sexual beliefs seem to be important vulnerability factors for sexual desire problems in MSM. Gay men with sexual dysfunction report higher beliefs about "sex as an abuse of top men's power" compared with gay men without sexual problems. In addition, gay men reported less dysfunctional sexual beliefs related to "macho ideas," "partner's power," and "partner's sexual satisfaction" compared to heterosexual men [86].

The combination of some illicit drugs and sexuality (Chemsex, Party and Play-PnP) among MSM has also some interesting connection with sexual desire. Even if a discussion of the chemsex phenomenon is out of the aims of the current review, Weatherburn et al. [87] reported that many MSM described an "insatiable and overpowering" increase of sex drive under the influence of drugs such as injected crystal methamphetamine. For some men suffering from lack of sexual desire, the use of drugs enhancing and prolonging the sexual activity represents a momentary relief. O'Byrne [88] described how gay men attending circuit parties use drugs either to fulfill sexual desires or overcome negative emotions. Being more disinhibited allowed them to engage in sexual experiences that they desire. In this sense, it should be recognized how the use of drugs, although very risky and harmful, may allow a different kind of liberation and a pleasurable sexual experience for some gay men [87].

\section{Sexual Fantasies}

Early studies $[89,90]$ highlighted that gay men seem to engage more frequently in erotic fantasies than heterosexuals, 
both during masturbation and partnered sexual activity. Gay men seem to be principally triggered by visual stimuli and oriented to body parts rather than real partners. An Italian study partially confirmed these premises, recognizing a central role to physical, emotional, and relational elements in the imagery [91]. Gay men reported more fantasies concerning exploratory (e.g., having an orgy), intimate (e.g., romantic scenes), and impersonal sexual activities (e.g., sex with strangers) than heterosexual men. No difference was found in paraphilic-related fantasies [92].

Schmitt [93] showed that gay men fantasize about having more than one sexual partner more often than heterosexual men, but less than bisexual men. Some MSM engage in online chat fantasizing about barebacking activities (e.g., unprotected anal intercourse) that is associated with possible sexual risktaking in real life [94]. Cuckolding fantasies (sexual arousal obtained by having a romantic partner engaging in sexual activity with someone else) were addressed in gay men, sharing many common elements with heterosexual-oriented studies on this topic. Frequent cuckolding fantasies were linked to several overlapping sexual interests such as group sex and voyeurism [95].

Gay men in the BDSM community showed a high frequency of fantasies including leather outfits, wrestling, special equipment and uniform scenes, rimming, anal intercourse, and dildos [96]. BDSMers seem to be more satisfied and less concerned about sexuality than the general population [97]. Overall, it should be recognized how giving space to personal erotic fantasies, sharing and exploring them in a safe environment might have a positive outcome on sexual satisfaction and quality of life [96, 97].

\section{Conclusions}

Lesbian and gay people showed a variety of sexual expressions that are hard to categorize referring to heteronormative sexual standards that are predominant in literature and clinical practice. Although sexual desire levels and related dysfunctions may not significantly differ from heterosexual cisgender people, evidence showed that lesbian and gay people may have specific sexual expressions and biopsychosocial factors influencing their sexual health. Negative sexual beliefs and attitudes may represent barriers to access to sexual health care. Addressing desire problems in this population should include assessment of sexual practices, frequency of sexual activity, couple discrepancies in desires levels, and erotic repertoires $[2 \bullet \bullet, 7]$. Accepting sexual fantasies and supporting disclosure with partners are important tools in sexual therapy and might foster personal growth and couple intimacy [98]. In this sense, professionals who attended educational programs in sexology seem to be the best references, for their formation and their personal attitudes, for clinical work with gay and lesbian patients complaining about sexual problems [99].

This review has some limitations that should be considered. Some studies did not differentiate between sexual orientation (e.g., lesbian and bisexual women) and used collective terms such as WSW, MSM, "other sexual orientations," "sexual minority women/men," or "non-heterosexual orientation." Differences reported might plausibly be attributed to factors other than sexual desire, such as differences in sexual definitions, or emphasis on frequency and practices over desire [30]. Nonetheless, most of the studies have focused on desire/ frequency mainly for partnered genital sexual activities, neglecting solo and non-genital practices. Considering the whole range of sexual possibilities, the scenery may sensibly change [100]. Due to these limitations, comparing and discussing evidences was quite challenging and the findings should be interpreted with caution.

Funding Information Open access funding provided by Università degli Studi di Roma La Sapienza within the CRUI-CARE Agreement.

\section{Compliance with Ethical Standards}

Conflict of Interest The authors declare that they have no conflict of interest.

Human and Animal Rights and Informed Consent This article does not contain any studies with human or animal subjects performed by any of the authors.

Open Access This article is licensed under a Creative Commons Attribution 4.0 International License, which permits use, sharing, adaptation, distribution and reproduction in any medium or format, as long as you give appropriate credit to the original author(s) and the source, provide a link to the Creative Commons licence, and indicate if changes were made. The images or other third party material in this article are included in the article's Creative Commons licence, unless indicated otherwise in a credit line to the material. If material is not included in the article's Creative Commons licence and your intended use is not permitted by statutory regulation or exceeds the permitted use, you will need to obtain permission directly from the copyright holder. To view a copy of this licence, visit http://creativecommons.org/licenses/by/4.0/.

\section{References}

Papers of particular interest, published recently, have been highlighted as:

- Of importance

- Of major importance

1 Mark K, Herbenick D, Fortenberry D, Sanders S, Reece M. The object of sexual desire: examining the "what" in "what do you desire?". J Sex Med. 2014;11(11):2709-19. https://doi.org/10.1111/jsm.12683.

2•• Nimbi FM, Tripodi F, Rossi R, Navarro-Cremades F, Simonelli C. Male sexual desire: an overview of biological, psychological, 
sexual, relational, and cultural factors influencing desire. Sexual Med Rev. 2020;8(1):59-91. https://doi.org/10.1016/j.sxmr.2018. 12.002 This article highlights the biopsychosocial factors influencing sexual desire in the male population.

3 Kaplan HS. The new sex therapy: active treatment of sexual dysfunctions. New York: Brunner/Mazel; 1974.

4 Kaplan HS. Disorders of sexual desire. New York: Brunner/Mazel; 1979.

5 Janssen E, McBride KR, Yarber W, Hill BJ, Butler SM. Factors that influence sexual arousal in men: a focus group study. Arch Sex Behav. 2008;37(2):252-65.

6 Prause N, Janssen E, Hetrick WP. Attention and emotional responses to sexual stimuli and their relationship to sexual desire. Arch Sex Behav. 2008;37(6):934-49.

7 Nimbi FM, Tripodi F, Rossi R, Simonelli C. Testing a conceptual model for men's sexual desire referring to automatic thoughts, emotions, sexual function, and sexism. J Sex Med. 2018;15(11): 1518-26. https://doi.org/10.1016/j.jsxm.2018.09.008.

8 Nimbi FM, Tripodi F, Rossi R, Simonelli C. Expanding the analysis of psychosocial factors of sexual desire in men. J Sex Med. 2018;15(2):230-44. https://doi.org/10.1016/j.jsxm.2017.11.227.

9 Nimbi FM, Tripodi F, Rossi R, Michetti PM, Simonelli C. Which psychosocial variables affect drive the most? Analysis of sexual desire in a group of Italian men. Int J Impot Res. 2019;31:410-23. https://doi.org/10.1038/s41443-018-0105-8.

10 Boysen GA, Fisher M, Dejesus M, Vogel DL, Madon S. The mental health stereotype about gay men: the relation between gay men's self-stereotype and stereotypes about heterosexual women and lesbians. J Soc Clin Psychol. 2011;30(4):329-60. https://doi. org/10.1521/jscp.2011.30.4.329.

11 Boysen GA, Vogel DL, Madon S, Wester SR. Mental health stereotypes about gay men. Sex Roles. 2006;54:69-82. https://doi. org/10.1007/s11199-006-8870-0.

12 Nichols M. Lesbian sexuality/female sexuality: rethinking 'lesbian bed death'. Sex Relatsh Ther. 2004;19(4):363-71. https://doi.org/ 10.1080/14681990412331298036.

13 Sorensen A. Lesbian stereotypes in the United States. Wiley Blackwell Encyclop Gender Sexual Stud. 2016. https://doi.org/ 10.1002/9781118663219.wbegss413.

14 Chmielewski JF. A listening guide analysis of lesbian and bisexual young women of color's experiences of sexual objectification. Sex Roles. 2017;77(7-8):533-49. https://doi.org/10.1007/s11199-0170740-4.

15 Blumstein P, Schwartz P. American couples. Money, work, sex. New York: William Morrow \& Co; 1987

16 Sobecki-Rausch JN, Brown O, Gaupp CL. Sexual dysfunction in lesbian women: a systematic review of the literature. Semin Reprod Med. 2017;35(5):448-59. https://doi.org/10.1055/s-00371604455.

17•• Rosenkrantz DE, Mark KP. The sociocultural context of sexually diverse women's sexual desire. Sex Cult. 2018;22(1):220-42. https://doi.org/10.1007/s12119-017-9462-6 This paper highlights the female sexual desire from a biopsychosocial perspective, discussing important factors connected to the expression of drive.

18 Scott SB, Ritchie L, Knopp K, Rhoades GK, Markman HJ. Sexuality within female same-gender couples: definitions of sex, sexual frequency norms, and factors associated with sexual satisfaction. Arch Sex Behav. 2018;47(3):681-92. https://doi.org/10. 1007/s10508-017-1077-3.

19 Downey JI, Friedman RC. Internalized homophobia in lesbian relationships. J Am Acad Psychoanal. 1995;23(3):435-47.

20 Spitalnick JS, McNair LD. Couples therapy with gay and lesbian clients: an analysis of important clinical issues. J Sex Marital Ther. 2005;31(1):43-56. https://doi.org/10.1080/00926230590475260.
21 Iasenza S. Queering the new view. Fem Psychol. 2008;18(4):53745. https://doi.org/10.1177/0959353508095535.

22 Iasenza S. Beyond "lesbian bed death". The passion and play in lesbian relationships. f Lesbian Stud. 2002;6(1):111-20. https:// doi.org/10.1300/J155v06n01_10.

23 van Rosmalen-Nooijens KAWL, Vergeer CM, Lagro-Janssen ALM. Bed death and other lesbian sexual problems unraveled: a qualitative study of the sexual health of lesbian women involved in a relationship. Women Health. 2008;48(3):339-62. https://doi.org/ 10.1080/03630240802463343.

24 Engeln-Maddox R, Miller SA, Doyle DM. Tests of objectification theory in gay, lesbian, and heterosexual community samples: mixed evidence for proposed pathways. Sex Roles. 2011;65(78):518-32. https://doi.org/10.1007/s11199-011-9958-8.

25 Cohen JN, Byers ES. Beyond lesbian bed death: enhancing our understanding of the sexuality of sexual-minority women in relationships. J Sex Res. 2014;51(8):893-903. https://doi.org/10.1080/ 00224499.2013 .795924$.

26 Hurlbert DF. Female sexuality: a comparative study between women in homosexual and heterosexual relationships. J Sex Marital Ther. 1993;19(4):315-27.

27 Matthews AK, Tartaro J, Hughes TL. A comparative study of lesbian and heterosexual women in committed relationships. J Lesbian Stud. 2002;7(1):101-14. https://doi.org/10.1300/ J155v07n01_07.

28 Gordon LE. Bringing the U-haul: embracing and resisting sexual stereotypes in a lesbian community. Sexualities. 2006;9(2):17192. https://doi.org/10.1177/1363460706063118.

29 Tracy JK, Junginger J. Correlates of lesbian sexual functioning. J Women's Health. 2007;16(4):499-509. https://doi.org/10.1089/ jwh.2006.0308.

30 Holmberg D, Blair KL. Sexual desire, communication, satisfaction, and preferences of men and women in same-sex versus mixed-sex relationships. J Sex Res. 2009;46(1):57-66. https:// doi.org/10.1080/00224490802645294.

31 Henderson AW, Lehavot K, Simoni JM. Ecological models of sexual satisfaction among lesbian/bisexual and heterosexual women. Arch Sex Behav. 2009;38(1):50-65. https://doi.org/10.1007/ s10508-008-9384-3.

32 Blair KL, Pukall CF. Can less be more? Comparing duration vs. frequency of sexual encounters in same-sex and mixed-sex relationships. Can J Hum Sex. 2014;23(2):123-36. https://doi.org/10. 3138/cjhs.2393.

33 Peixoto MM, Nobre P. Prevalence of sexual problems and associated distress among lesbian and heterosexual women. J Sex Marital Ther. 2015;41(4):427-39. https://doi.org/10.1080/0092623X. 2014.918066

34 Ronson A, Wood JR, Milhausen RR. Current research on sexual response and sexual functioning among lesbian women. Curr Sex Health Rep. 2015;7(3):191-7. https://doi.org/10.1007/s11930015-0056-8.

35 Cherkasskaya E, Rosario M. The relational and bodily experiences theory of sexual desire in women. Arch Sex Behav. 2019;48(6): 1659-81. https://doi.org/10.1007/s10508-018-1212-9.

36 Rothblum ED. An overview of same-sex couples in relationships: a research area still at sea. In: Contemporary perspectives on lesbian, gay, and bisexual identities. New York: Springer; 2009. p. 113-39.

37 Kurdek LA. Differences between partners from heterosexual, gay, and lesbian cohabiting couples. J Marriage Fam. 2006;68(2):509 28. https://doi.org/10.1111/j.1741-3737.2006.00268.x.

38 Peplau LA, Fingerhut AW. The close relationships of lesbians and gay men. Annu Rev Psychol. 2007;58:405-24. https://doi.org/10. 1146/annurev.psych.58.110405.085701. 
39 Umberson D, Thomeer MB, Lodge AC. Intimacy and emotion work in lesbian, gay, and heterosexual relationships. J Marriage Fam. 2015;77(2):542-56. https://doi.org/10.1111/jomf.12178.

40 Nimbi FM, Tripodi F, Simonelli C, Nobre P. Sexual dysfunctional beliefs questionnaire (SDBQ): translation and psychometric properties of the Italian version. Sexologies. 2019;28(2):e11-27. https://doi.org/10.1016/j.sexol.2018.09.003.

41 Paine EA, Umberson D, Reczek C. Sex in midlife: women's sexual experiences in lesbian and straight marriages. J Marriage Fam. 2019;81(1):7-23. https://doi.org/10.1111/jomf.12508 This article shows important evidences on aging, sexuality and couple experiences in women.

42 Dawson SJ, Suschinsky KD, Lalumiere ML. Sexual fantasies and viewing times across the menstrual cycle: a diary study. Arch Sex Behav. 2012;41(1):173-83. https://doi.org/10.1007/s10508-0129939-1.

43 Joyal CC, Cossette A, Lapierre V. What exactly is an unusual sexual fantasy? J Sex Med. 2015;12(2):328-40. https://doi.org/ 10.1111/jsm.12734.

44 Robinson JD, Parks CW. Lesbian and bisexual women's sexual fantasies, psychological adjustment, and close relationship functioning. J Psychol Hum Sex. 2004;15(4):185-203. https://doi.org/ 10.1300/J056v15n04_03.

45 Thorne A, Coupland J. Articulations of same-sex desire: lesbian and gay male dating advertisements. J Socioling. 1998;2(2):23357. https://doi.org/10.1111/1467-9481.00042.

46 Diamond LM. 'I'm straight, but I kissed a girl': the trouble with American media representations of female-female sexuality. Fem Psychol. 2005;15(1):104-10. https://doi.org/10.1177/ 0959353505049712.

47. Tortora C, D’Urso G, Nimbi FM, Pace U, Marchetti D, Fontanesi L. Sexual fantasies and stereotypical gender roles: the influence of sexual orientation, gender and social pressure in a sample of Italian young-adults. Front Psychol. 2020;10:2864. https://doi.org/10. 3389/fpsyg.2019.02864 This article compares gender and sexual orientations regarding erotic fantasies and gender role expressions.

48 Bivona JM, Critelli JW, Clark MJ. Women's rape fantasies: an empirical evaluation of the major explanations. Arch Sex Behav. 2012;41(5):1107-19. https://doi.org/10.1007/s10508-012-9934-6.

49 Simmons JL. Public stereotypes of deviants. Soc Probl. 1965;13: 223-32. https://doi.org/10.2307/798906.

50 Levitt EE, Klassen AD. Public attitudes toward homosexuality: part of the 1970 national survey by the Institute for Sex Research. J Homosex. 1974;1:29-43. https://doi.org/10.1300/ J082v01n01_03.

51 Madon S. What do people believe about gay males? A study of stereotype content and strength. Sex Roles. 1997;37:663-85. https://doi.org/10.1007/BF02936334.

52 Lippa RA. The relation between sex drive and sexual attraction to men and women: a cross-national study of heterosexual, bisexual, and homosexual men and women. Arch Sex Behav. 2007;36(2): 209-22. https://doi.org/10.1007/s10508-006-9146-z.

53 Welling LL, Singh K, Puts DA, Jones BC, Burriss RP. Selfreported sexual desire in homosexual men and women predicts preferences for sexually dimorphic facial cues. Arch Sex Behav. 2013;42(5):785-91. https://doi.org/10.1007/s10508-012-0059-8.

54 Peixoto M. Sexual satisfaction, solitary, and dyadic sexual desire in men according to sexual orientation. J Homosex. 2019;66(6):76979. https://doi.org/10.1080/00918369.2018.1484231.

55 Bourne A, Hammond G, Hickson F, Reid D, Schmidt AJ, Weatherburn P. What constitutes the best sex life for gay and bisexual men? Implications for HIV prevention. BMC Public Health. 2013;13(1):1083. https://doi.org/10.1186/1471-2458-131083.
56 Mark KP, Garcia JR, Fisher HE. Perceived emotional and sexual satisfaction across sexual relationship contexts: gender and sexual orientation differences and similarities. Can J Hum Sex. 2015;24(2):120-30. https://doi.org/10.3138/cjhs.242-A8.

57 Perera PADMP, Abeygunasekera N, Gunewardhana CU, Kumarasinghe NH, Mohedeen SB. Potential sexual addiction (PSA) among men who have sex with men (MSM) who attended STD clinic, Kalubowila: a descriptive cross-sectional study. Sri Lanka J Sexual Health HIV Med. 2018;4:6-10. https://doi.org/ 10.4038/joshhm.v4i0.75.

58 Weinstein A, Katz L, Eberhardt H, Cohen K, Lejoyeux M. Sexual compulsion - relationship with sex, attachment and sexual orientation. J Behav Addict. 2015;4(1):22-6. https://doi.org/10.1556/ JBA.4.2015.1.6.

59 Pachankis JE, Rendina HJ, Restar A, Ventuneac A, Grov C, Parsons JT. A minority stress - emotion regulation model of sexual compulsivity among highly sexually active gay and bisexual men. Health Psychol. 2015;34(8):829-40. https://doi.org/10.1037/ hea0000180.

60 Parsons JT, Kelly BC, Bimbi DS, DiMaria L, Wainberg ML, Morgenstern J. Explanations for the origins of sexual compulsivity among gay and bisexual men. Arch Sex Behav. 2008;37(5):81726. https://doi.org/10.1007/s10508-007-9218-8.

61 Štulhofer A, Jurin T, Briken P. Is high sexual desire a facet of male hypersexuality? Results from an online study. J Sex Marital Ther. 2016;42(8):665-80. https://doi.org/10.1080/0092623X.2015. 1113585.

62 Carvalho J, Štulhofer A, Vieira AL, Jurin T. Hypersexuality and high sexual desire: exploring the structure of problematic sexuality. J Sex Med. 2015;12(6):1356-67. https://doi.org/10.1111/jsm. 12865.

63 Peixoto MM, Nobre P. Prevalence of sexual problems and associated distress among gay and heterosexual men. Sex Relatsh Ther. 2015;30(2):211-25. https://doi.org/10.1080/14681994.2014. 986084 .

64 Rosser B, Metz M, Bockting W, Buroker T. Sexual difficulties, concerns, and satisfaction in homosexual men: an empirical study with implications for HIV prevention. Journal of Sex \& Marital Therapy. 1997;23:61-73. https://doi.org/10.1080/ 00926239708404418.

65 Lau J, Kim J, Tsui H. Prevalence and factors of sexual problems in Chinese males and females having sex with the same-sex partner in Hong-Kong: a population-based study. Int J Impot Res. 2006;1: 130-40. https://doi.org/10.1038/sj.ijir.3901368.

66 Lau J, Kim J, Tsui H. Prevalence and sociocultural predictors of sexual dysfunction among Chinese men who have sex with men in Hong Kong. J Sex Med. 2008;5:2766-79. https://doi.org/10.1743/ 6109.2008.00892.x.

67 Seibel S, Rosser B, Horvath K, Evans C. Sexual dysfunction, paraphilias and their relationship to childhood abuse in men who have sex with men. Int J Sex Health. 2009;21:79-86. https://doi. org/10.1080/19317610902773062.

68 Hirshfield S, Chiasson M, Wagmiller R, Remien R, Humberstone M, Scheinmann R, et al. Sexual dysfunction in an internet sample of U.S. men who have sex with men. J Sex Med. 2010;7:3104-14. https://doi.org/10.1111/j.1743-6109.2009.01636.x.

69 Bancroft J, Janssen E. The dual control model of male sexual response: a theoretical approach to centrally mediated erectile dysfunction. Neurosci Biobehav Rev. 2000;24(5):571-9. https://doi. org/10.1016/s0149-7634(00)00024-5.

70 Kowalczyk R, Kaluga M, Jacek K, Nowosielski K. Sexual excitation, sexual inhibition and a prevalence of sexual disorders among msm and heterosexual men. European Psychiatry. 2017;41:S850. https://doi.org/10.1016/j.eurpsy.2017.01.1686. 
71 Patterson CJ. Family relationships of lesbians and gay men. J Marriage Fam. 2000;62:1052-69. https://doi.org/10.1111/j.17413737.2000.01052.x.

72. Philpot SP, Duncan D, Ellard J, Bavinton BR, Grierson J, Prestage G. Negotiating gay men's relationships: how are monogamy and non-monogamy experienced and practised over time? Cult Health Sex. 2018;20(8):915-28. https://doi.org/10.1080/13691058.2017. 1392614 This article represents an important dissertation about monogamy and non-monogamy in gay relationships.

73 Finn M. Monogamous order and the avoidance of chaotic excess. Psychol Sexual. 2012;3:123-36. https://doi.org/10.1080/ 19419899.2011.551834.

74 Parsons JT, Starks TJ, DuBois S, Grov C, Golub SA. Alternatives to monogamy among gay male couples in a community sample: implications for mental health and sexual health. Arch Sex Behav. 2013;42:303-12. https://doi.org/10.1007/s10508-011-9885-3.

75 Duncan D, Prestage G, Grierson J. Trust, commitment, love and sex: HIV, monogamy, and gay men. J Sex Marital Ther. 2015;41(4):345-60. https://doi.org/10.1080/0092623X.2014. 915902.

76 Pope M, Wierzalis EA, Barret B, Rankins M. Sexual and intimacy issues for aging gay men. Adultspan J. 2011;6(2):68-82. https:// doi.org/10.1002/j.2161-0029.2007.tb00033.x.

77 Murray SH, Milhausen RR, Graham CA, Kuczynski L. A qualitative exploration of factors that affect sexual desire among men aged 30 to 65 in long-term relationships. J Sex Res. 2017;54(3): 319-30. https://doi.org/10.1080/00224499.2016.1168352.

78 Bancroft J, Janssen E, Strong D, Vukadinovic Z. The relation between mood and sexuality in gay men. Arch Sex Behav. 2003;32(3):231-42. https://doi.org/10.1023/A:1023461500810.

79 Lemke R, Weber M. That man behind the curtain: investigating the sexual online dating behavior of men who have sex with men but hide their same-sex sexual attraction in offline surroundings. J Homosex. 2017;64(11):1561-82. https://doi.org/10.1080/ 00918369.2016.1249735

80 Mark KP, Vowels LM, Bennett S, Norwick J. Sources for the formation of sexual values in lesbian, gay, bisexual, and straight adults and the impact on sexual satisfaction and desire. Am J Sexual Educ. 2018;13(4):399-410. https://doi.org/10.1080/ 15546128.2018.1470950.

81 Perry NS, Nelson KM, Carey MP. Diversity of psychosocial syndemic indicators and associations with sexual behavior with male and female partners among early adolescent sexual minority males. LGBT health. 2019;6(8):386-92. https://doi.org/10.1089/ lgbt.2019.0113.

82 Lacefield K, Negy C. Non-erotic cognitive distractions during sexual activity in sexual minority and heterosexual young adults. Arch Sex Behav. 2012;41(2):391-400. https://doi.org/10.1007/s10508011-9792-7.

83 Vansintejan J, Janssen J, Van De Vijver E, Vandevoorde J, Devroey D. The gay men sex studies: prevalence of sexual dysfunctions in Belgian HIV+ gay men. HIV/AIDS. 2013;5:89. https://doi.org/10.2147/HIV.S43962.

84 Drumright LN, Strathdee SA, Little SJ, Araneta MRG, Slymen DJ, Malcarne VL, et al. Unprotected anal intercourse and substance use before and after HIV diagnosis among recently HIV-infected men who have sex with men. Sex Transm Dis. 2007;34(6):401-7. https://doi.org/10.1097/01.olq.0000245959.18612.a1.

85 Platteau T, Nöstlinger C, Schrooten W, Kenyon C, van Lankveld JJ, Colebunders R, et al. Sexual inactivity among men who have sex with men living with hiv in Europe. Int J Sex Health.
2015;27(2):83-92. https://doi.org/10.1080/19317611.2014. 956852

86 Peixoto MM, Nobre P. Dysfunctional sexual beliefs: a comparative study of heterosexual men and women, gay men, and lesbian women with and without sexual problems. J Sex Med. 2014;11(11): 2690-700. https://doi.org/10.1111/jsm.12666.

87 Weatherburn P, Hickson F, Reid D, Torres-Rueda S, Bourne A. Motivations and values associated with combining sex and illicit drugs ('chemsex') among gay men in South London: findings from a qualitative study. Sex Transm Infect. 2017;93(3):203-6. https:// doi.org/10.1136/sextrans-2016-052695.

88 O'Byrne P. Examining the intersection of desire, drugs and place among gay men. J Res Nurs. 2013;18(3):265-76. https://doi.org/ 10.1177/1744987111415040.

89 Masters WH, Johnson VE. Homosexuality in perspective. Boston: Little Brown; 1979.

90 Crépault C, Couture M. Men's erotic fantasies. Arch Sex Behav. 1980;9:565-81. https://doi.org/10.1007/BF01542159.

91 Cacioppo M, Vizzari V, Corica F, Maestri V, Simonelli C. An exploratory study on male homosexual erotic imagery. Sexologies. 2009;18(1):44-50. https://doi.org/10.1016/j.sexol. 2007.12.007.

92 Bhugra D, Rahman Q, Bhintade R. Sexual fantasy in gay men in India: a comparison with heterosexual men. Sex Relatsh Ther. 2006;21(02):197-207. https://doi.org/10.1080/ 14681990600554207.

93 Schmitt DP, Alcalay L, Allik J, Ault L, Austers I, Bennett KL, et al. Universal sex differences in the desire for sexual variety: tests from 52 nations, 6 continents, and 13 islands. J Pers Soc Psychol. 2003;85(1):85-104. https://doi.org/10.1037/0022-3514.85.1.85.

94 Adam PC, Murphy DA, de Wit JB. When do online sexual fantasies become reality? The contribution of erotic chatting via the internet to sexual risk-taking in gay and other men who have sex with men. Health Educ Res. 2011;26(3):506-15. https://doi.org/ 10.1093/her/cyq085.

95 Lehmiller JJ, Ley D, Savage D. The psychology of gay men's cuckolding fantasies. Arch Sex Behav. 2018;47(4):999-1013. https://doi.org/10.1007/s10508-017-1096-0.

96 Nordling N, Sandnabba NK, Santtila P, Alison L. Differences and similarities between gay and straight individuals involved in the sadomasochistic subculture. J Homosex. 2006;50(2-3):41-57. https://doi.org/10.1300/J082v50n02 03.

97 Botta D, Nimbi FM, Tripodi F, Silvaggi M, Simonelli C. Are role and gender related to sexual function and satisfaction in men and women practicing BDSM? J Sex Med. 2019;16(3):463-73. https:// doi.org/10.1016/j.jsxm.2019.01.001.

98 Newbury R, Hayter M, Wylie KR, Riddell J. Sexual fantasy as a clinical intervention. Sex Relatsh Ther. 2012;27(4):358-71. https://doi.org/10.1080/14681994.2012.733816.

99 Nimbi FM, Viozzi E, Tripodi F, Simonelli C, Baiocco R. Could educational programs in sexology have an influence on attitudes towards same-sex marriage and parenting? Sexologies. 2020; in press, online published. doi: https://doi.org/10.1016/j.sexol.2020. 01.001

100 Burri A, Rahman Q, Santtila P, Jern P, Spector T, Sandnabba K. The relationship between same-sex sexual experience, sexual distress, and female sexual dysfunction. J Sex Med. 2012;9(1):198206. https://doi.org/10.1111/j.1743-6109.2011.02538.x.

Publisher's Note Springer Nature remains neutral with regard to jurisdictional claims in published maps and institutional affiliations. 